\title{
Inflammatory Myofibroblastic Tumor of the Urinary Bladder with Benign Pelvic Lymph Node Enlargement: A Case Report
}

\author{
Kazuaki Machioka ${ }^{a}$ Yasuhide Kitagawa $^{a} \quad$ Kouji Izumi $^{a} \quad$ Seiko Kitamura ${ }^{b}$ \\ Hiroko Ikeda ${ }^{b}$ Mikio Namiki ${ }^{a}$ \\ ${ }^{a}$ Department of Integrative Cancer Therapy and Urology, Graduate School of Medical \\ Science, Kanazawa University, and 'Division of Pathology, Kanazawa University Hospital, \\ Kanazawa University, Kanazawa, Japan
}

\section{Key Words}

Inflammatory myofibroblastic tumor · Urinary bladder $\cdot$ Lymph node swelling

\begin{abstract}
Inflammatory myofibroblastic tumors (IMTs) rarely occur in the urinary bladder. It is apparently difficult to distinguish these tumors from other malignant spindle cell proliferations. Herein, we report a case of IMT of the urinary bladder with enlarged pelvic lymph nodes. The definitive pathological diagnosis could not be established by biopsy. Instead, the diagnosis of IMT of the urinary bladder was determined by a positive reaction to anaplastic lymphoma kinase by immunohistochemistry after radical cystectomy. No malignant findings were observed on histopathological evaluations of the enlarged lymph nodes.
\end{abstract}

(C) 2014 S. Karger AG, Basel

\section{Introduction}

Inflammatory myofibroblastic tumor (IMT) is an unusual mesenchymal tumor composed of neoplastic myofibroblasts and a conspicuous inflammatory infiltrate that can arise in a wide variety of anatomic locations [1]. IMT rarely occurs in the urinary bladder, and IMTs of the urinary bladder are difficult to distinguish from other malignant spindle cell proliferations [2-4]. Herein, we report a case of IMT of the urinary bladder with pelvic lymph node enlargement. 


\section{Case Presentation}

A 69-year-old female with a history of hysterectomy secondary to myoma uteri suffered from lower abdominal discomfort and residual urine sensation. On a visit to her general practitioner, a retrovesical tumor was detected on ultrasonography. Thus, she was referred to our department. Cystoscopic examination showed edematous inflammatory changes of the mucosa of the trigone and posterior bladder wall. Urine cytology was negative. CT and MRI revealed a retrovesical tumor on the left posterior wall of the urinary bladder and several bilateral enlarged lymph nodes proximal to the common and external iliac arteries (fig. 1). The uterus and left ovary were not observed. Transvaginal needle biopsy was performed. Histopathological examination of the biopsy specimen revealed proliferation of spindle-shaped cells with a high nuclear-cytoplasmic ratio and prominent nuclei on a background of plasma cells and lymphocytes (fig. 2). In immunohistochemical studies, these specimens presented positive reactions for vimentin and cytokeratin AE1/AE3 and negative reactions for epithelial membrane antigen, $\alpha$-smooth muscle actin, S-100 protein, and CD34; therefore, sarcomatoid carcinoma was highly suspected. Immunohistochemical staining for anaplastic lymphoma kinase (ALK) was not performed at that time.

Two months after the initial visit, tumor growth was evidenced on CT, and positron emission tomography revealed the accumulation on tumor. These findings suggested the malignant potential of the tumor, but there were no standard treatment options regarding chemotherapy and radiation because of the atypical findings on the biopsy. Radical cystectomy, pelvic lymph node dissection, and ileal conduit construction were performed. The immunohistochemical profile of the surgical specimen was similar to that of the biopsy specimen; however, the cytokeratin AE1/AE3 staining was focal and weak. Histopathological diagnosis of IMT of the bladder was determined by a positive reaction to ALK on immunohistochemical analysis (fig. 3). No malignant findings were observed by histopathological examination of the enlarged lymph nodes. After surgery, no recurrence of the disease was detected during a 4-year follow-up period.

\section{Discussion}

IMT of the urinary bladder was first reported in 1980 [2] and is characterized by atypical spindle cell proliferation and inflammatory cell infiltrates primarily involving lymphocytes and plasma cells. IMTs resemble malignant spindle cell tumors both morphologically and immunologically, and the differential pathological diagnosis is considered difficult [2-4]. In particular, the immunohistochemical expression of both epithelial and myogenic markers, as observed in the biopsy specimen of the present case, may lead to a misdiagnosis of sarcomatoid carcinoma, leiomyosarcoma, or rhabdomyosarcoma [3, 4]. Recent reports have indicated that ALK, which was originally identified as a protein overexpressed in anaplastic large-cell lymphoma, was overexpressed in a substantial proportion of IMTs [4-8]. The positive finding of ALK by immunohistochemistry in up to $87.5 \%$ of the IMTs can be useful for the differentiation of IMTs from other malignant spindle cell lesions [4-8]. In the present case, the definitive pathological diagnosis was made by ALK immunoexpression in the surgical specimen. If the immunohistochemical study for ALK had been performed in the biopsy specimens, the pathological diagnosis of IMT of the urinary bladder might have been established prior to cystectomy.

In most reported cases of IMTs of the urinary bladder, surgical resections, including transurethral resection and partial and radical cystectomy, were performed; the complete 
surgical resection in previous cases was important to avoid local recurrence $[3,4,9]$. There was a report of unresectable IMTs successfully treated with steroids and non-steroidal antiinflammatory drugs [10]; however, a case of IMTs of the urinary bladder with malignant transformation and multiple metastases was also reported [11]. In the present case, the preoperative CT findings indicating tumor growth and multiple lymph node enlargements were thought to be suggestive of malignancy and were considered atypical compared to the few previous reports of IMT cases. Therefore, surgical resection might not have been avoidable even if the definitive pathological diagnosis had been made preoperatively. In the present case, the tumor was located in the trigone and posterior bladder wall, which are unusual tumor locations because it was previously reported that the most frequent tumor location was the bladder dome [12]. Thus, given the rarity of IMTs of the urinary bladder and the tumor location, radical cystectomy was selected as the operative procedure. Fortunately, no recurrence of the disease has been detected so far. However, further observation will be needed in the present case.

\section{Disclosure Statement}

The authors have no conflicts of interest to declare.

\section{References}

$\checkmark 1$ Coffin CM, Watterson J, Priest JR, Dehner LP: Extrapulmonary inflammatory myofibroblastic tumor (inflammatory pseudotumor). A clinicopathologic and immunohistochemical study of 84 cases. Am J Surg Pathol 1995;19:859-872.

12 Roth JA: Reactive pseudosarcomatous response in urinary bladder. Urology 1980;16:635-637.

-3 Iczkowski KA, Shanks JH, Gadaleanu V, Cheng L, Jones EC, Neumann R, Nascimento AG, Bostwick DG: Inflammatory pseudotumor and sarcoma of urinary bladder: differential diagnosis and outcome in thirtyeight spindle cell neoplasms. Mod Pathol 2001;14:1043-1051.

-4 Montgomery EA, Shuster DD, Burkart AL, Esteban JM, Sgrignoli A, Elwood L, Vaughn DJ, Griffin CA, Epstein JI: Inflammatory myofibroblastic tumors of the urinary tract: a clinicopathologic study of 46 cases, including a malignant example inflammatory fibrosarcoma and a subset associated with high-grade urothelial carcinoma. Am J Sug Pathol 2006;30:1502-1512.

5 Cook JR, Dehner LP, Collins MH, Ma Z, Morris SW, Coffin CM, Hill DA: Anaplastic lymphoma kinase (ALK) expression in the inflammatory myofibroblastic tumor: a comparative immunohistochemical study. Am J Surg Pathol 2001;25:1364-1371.

6 Sukov WR, Cheville JC, Carlson AW, Shearer BM, Piatigorsky EJ, Grogg KL, Sebo TJ, Sinnwell JP, Ketterling RP: Utility of ALK-1 protein expression and ALK rearrangements in distinguishing inflammatory myofibroblastic tumor from malignant spindle cell lesions of the urinary bladder. Mod Pathol 2007;20:592603.

7 Tsuzuki T, Magi-Galluzzi C, Epstein JI: ALK-1 expression in inflammatory myofibroblastic tumor of the urinary bladder. Am J Surg Pathol 2004;28:1609-1614.

-8 Rao RN, Ranjan P, Singla N, Pandey R: Inflammatory myofibroblastic tumor of the urinary bladder diagnosed by anaplastic lymphoma kinase immunostaining. Urol Ann 2012;4:115-118.

-9 Wei L, Jianbo L, Qiang W, Hai Y, Zhixiang L: Inflammatory myofibroblastic tumour of the bladder: case report and review of the literature. Can Urol Assoc J 2013;7:E237-E240.

10 Przkola R, Bolder U, Schwarz S, Jauch KW, Spes J, Andreesen A, Mackensen A: Regression of nonresectable inflammatory myofibroblastic tumours after treatment with nonsteroidal anti-inflammatory drugs. Eur J Clin Invest 2004;34:320-321.

11 Kim HW, Choi YH, Kang SM, Ku JY, Ahn JH, Kim JM, Chung JM, Ha HK, Chung MK: Malignant inflammatory myofibroblastic tumor of the bladder with rapid progression. Korean J Urol 2012;53:657-661.

-12 Houben CH, Chan A, Lee KH, Tam YH, To KF, Cheng W, Yeung CK: Inflammatory myofibroblastic tumor of the bladder in children: what can be expected? Pedatr Surg Int 2007;23:815-819. 


\section{Case Reports in Oncology}

\begin{tabular}{l|l}
\hline Case Rep Oncol 2014;7:571-575 \\
\hline DOI: 10.1159/000366269 & $\begin{array}{l}@ 2014 \text { S. Karger AG, Basel } \\
\text { www.karger.com/cro }\end{array}$ \\
\hline
\end{tabular}

Machioka et al.: Inflammatory Myofibroblastic Tumor of the Urinary Bladder with Benign Pelvic Lymph Node Enlargement: A Case Report

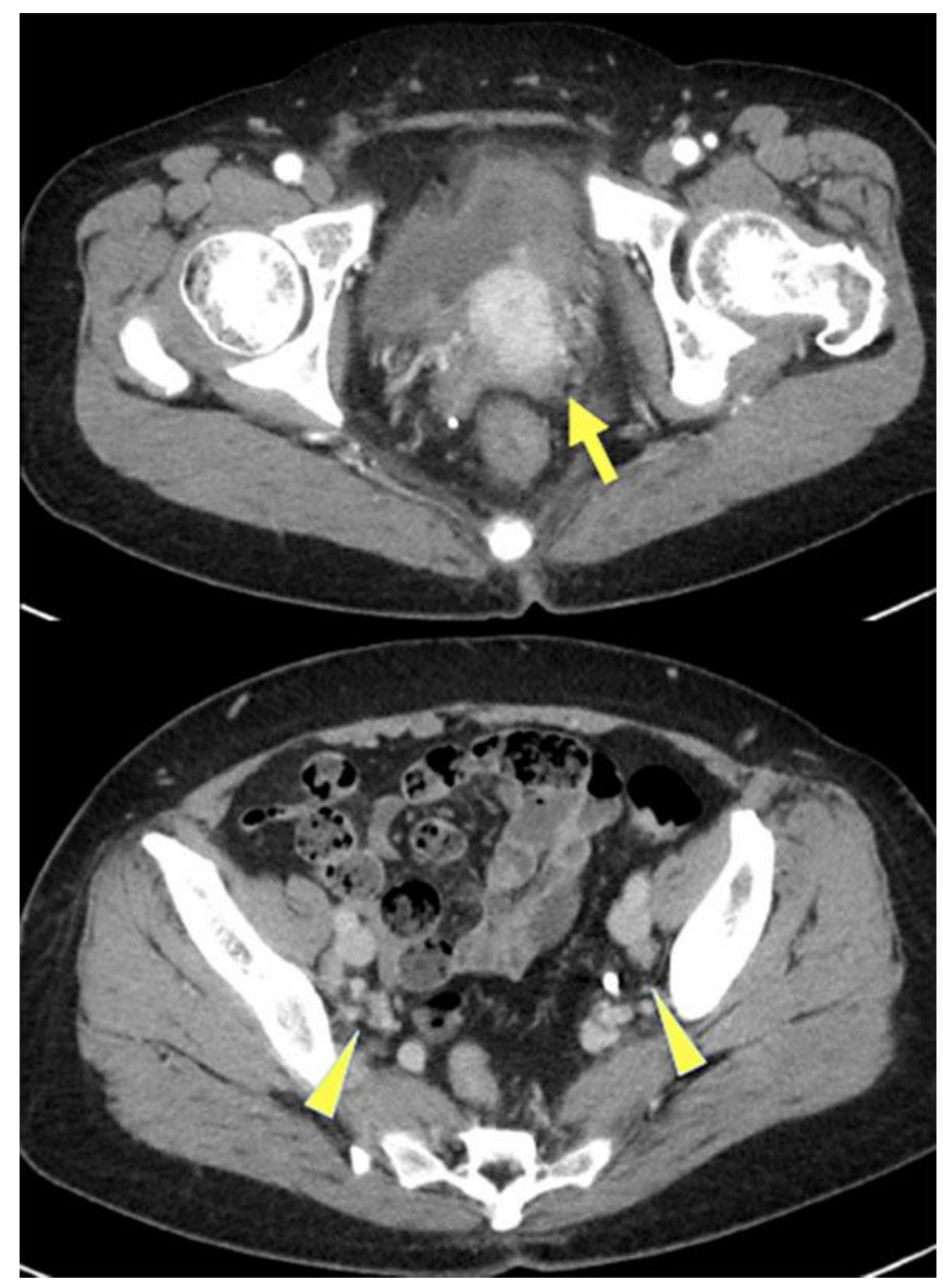

Fig. 1. CT image showing a retrovesical mass on the left posterior wall of the urinary bladder (arrow) and several bilateral enlarged lymph nodes proximal to the common and external iliac arteries (arrowheads). 


\section{Case Reports in Oncology}

Case Rep Oncol 2014;7:571-575

Machioka et al.: Inflammatory Myofibroblastic Tumor of the Urinary Bladder with Benign Pelvic Lymph Node Enlargement: A Case Report

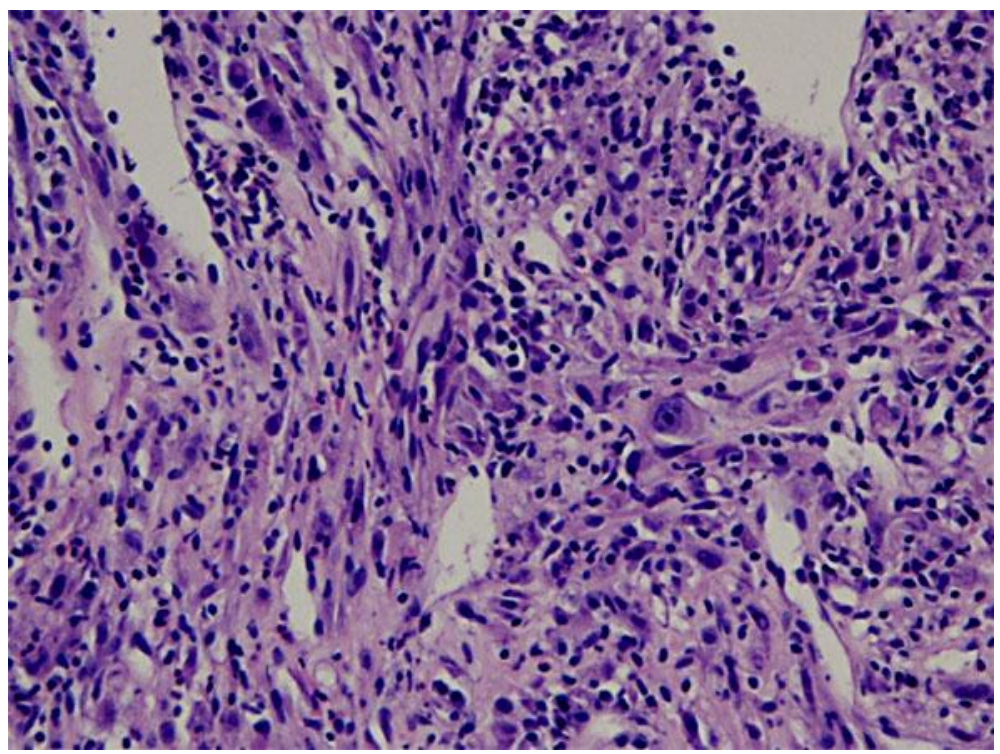

Fig. 2. Microscopic appearance of the tumor biopsy specimen showing proliferation of spindle-shaped cells with a high nuclear-cytoplasmic ratio and prominent nuclei on a background of plasma cells and lymphocytes (HE).

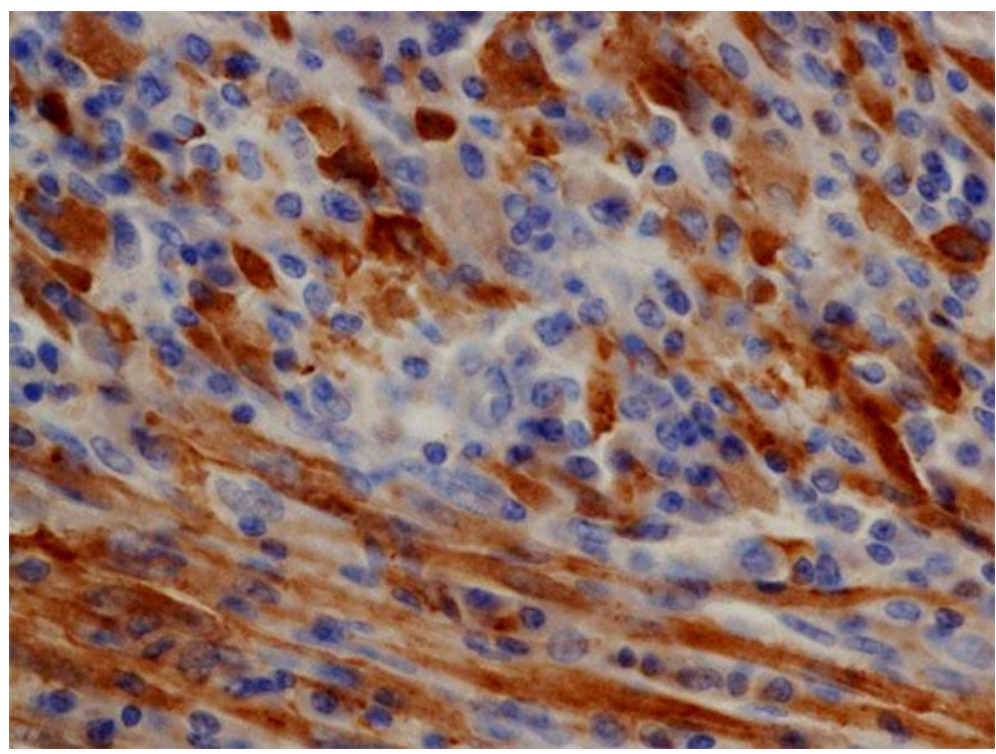

Fig. 3. ALK immunohistochemical staining in a surgical specimen of the tumor. 